\title{
Persistence of differences between dairy cows categorized as low or high methane emitters, as estimated from milk mid-infrared spectra and measured by GreenFeed
}

\author{
T. M. Denninger, ${ }^{1,2}$ F. Dohme-Meier, ${ }^{1 *}$ L. Eggerschwiler, ${ }^{1}$ A. Vanlierde, ${ }^{3}$ F. Grandl,,${ }^{4,5}$ B. Gredler, ${ }^{4}$ M. Kreuzer, ${ }^{2}$ \\ A. Schwarm, ${ }^{2,6}$ and A. Münger ${ }^{1}$ \\ ${ }^{1}$ Agroscope, Ruminant Research Unit, Route de la Tioleyre 4, 1725 Posieux, Switzerland \\ ${ }^{2}$ ETH Zurich, Institute of Agricultural Sciences, Universitaetstrasse 2, 8092 Zurich, Switzerland \\ ${ }^{3}$ Walloon Agricultural Research Centre, Valorisation of Agricultural Products Department, Chaussée de Namur, 24, B-5030 Gembloux, Belgium \\ ${ }^{4}$ Qualitas AG, Chamerstrasse 56, 6300 Zug, Switzerland \\ ${ }^{5}$ LKV Bayern e.V., Landsberger Str. 282, 80687 München, Germany \\ ${ }^{6}$ Department of Animal and Aquacultural Sciences, Norwegian University of Life Sciences, Arboretveien 6, 1433 Ås, Norway
}

\section{ABSTRACT}

Currently, various attempts are being made to implement breeding schemes aimed at producing low methane $\left(\mathrm{CH}_{4}\right)$ emitting cows. We investigated the persistence of differences in $\mathrm{CH}_{4}$ emission between groups of cows categorized as either low or high emitters over a 5-mo period. Two feeding regimens (pasture vs. indoors) were used. Early- to mid-lactation Holstein Friesian cows were categorized as low or high emitters ( $\mathrm{n}=10$ each) retrospectively, using predictions from milk mid-infrared (MIR) spectra, before the start of the experiment. Data from MIR estimates and from measurements with the GreenFeed (GF; C-Lock Technology Inc., Rapid City, SD) system over the 5-mo experiment were combined into 7-, 14-, and 28-d periods. Feed intake, eating and ruminating behavior, and ruminal fluid traits were determined in two 7-d measurement periods in the grazing season. The $\mathrm{CH}_{4}$ emission data were analyzed using a split-plot ANOVA, and the repeatability of each of the applied methods for determining $\mathrm{CH}_{4}$ emission was calculated. Traits other than $\mathrm{CH}_{4}$ emission were analyzed for differences between low and high emitters using a linear mixed model. The initial category-dependent differences in daily $\mathrm{CH}_{4}$ production persisted over the subsequent 5 mo and across 2 feeding regimens with both methods. The repeatability analysis indicated that the biweekly milk control scheme, and even a monthly scheme as practiced on farms, might be sufficient for confirming category differences. However, the relationship between $\mathrm{CH}_{4}$ data estimated by MIR and measured with GF for individual cows was weak $\left(\mathrm{R}^{2}=0.26\right)$. The categorization based on $\mathrm{CH}_{4}$

Received April 15, 2019.

Accepted August 14, 2019.

*Corresponding author: frigga.dohme-meier@agroscope.admin.ch production also generated differences in $\mathrm{CH}_{4}$ emission per kilogram of milk; differentiation between cow categories was not persistent based on milk MIR spectra and GF. Compared with the high emitters, low emitters tended to show a lower acetate-to-propionate ratio in ruminal volatile fatty acids, whereas feed intake and ruminating time did not differ. Interestingly, the low emitters spent less time eating than the high emitters. In conclusion, the $\mathrm{CH}_{4}$ estimation from analyzing the milk MIR spectra is an appropriate proxy to form and regularly control categories of cows with different $\mathrm{CH}_{4}$ production levels. The categorization was also sufficient to secure similar and persistent differences in emission intensity when estimated by MIR spectra of the milk. Further studies are needed to determine whether MIR data from individual cows are sufficiently accurate for breeding.

Key words: methane emission, among-animal differences, eating behavior, mid-infrared

\section{INTRODUCTION}

The European Union has committed to reducing its greenhouse gas emissions by $20 \%$ by 2020 , relative to 1990 levels. Methane $\left(\mathrm{CH}_{4}\right)$ is a greenhouse gas with a global warming effect that is 32 times as high as that of carbon dioxide (Holmes et al., 2013). The global livestock sector (mainly ruminants) is responsible for $18 \%$ of the anthropogenic greenhouse gas emissions (Steinfeld et al., 2006). Recently, interest in including low $\mathrm{CH}_{4}$ emission as a goal in breeding programs has substantially increased. This increased interest was triggered by studies showing that $\mathrm{CH}_{4}$ emission is a heritable trait in ruminants (Lassen and Løvendahl, 2016). Measuring $\mathrm{CH}_{4}$ production (MeP; g/d) with different techniques reveals considerable variability among individuals fed the same diet (Garnsworthy et al., 2012), 
which is another condition for breeding success. If the between-animal differences are consistent over time and with different diets, animal breeding might be a successful mitigation strategy. In comparison to feeding measures, breeding strategies need more time to have an impact, but they are cumulative and permanent. Their implementation requires accurate, cost-efficient, robust measurements or estimates on a very large number of animals, preferably with such evaluations done under farm conditions. The animal throughput of existing methods to quantify $\mathrm{CH}_{4}$ emissions, such as the most accurate technical solution-respiration chambers (RC) - is far too low for breeding purposes. An ideal approach would therefore be to develop a suitable proxy, that is, an indicator that reliably predicts $\mathrm{CH}_{4}$ emission without direct measurements. One of the most advanced proxies consists of predicting $\mathrm{CH}_{4}$ emissions from milk mid-infrared (MIR) spectral data using a calibration equation (Vanlierde et al., 2015) that has been validated with RC data (Vanlierde et al., 2016). These spectra are available from each cow in monthly or even biweekly intervals, given that farmers participate in widespread milk control recording schemes. Vanlierde et al. (2016) concluded that the prediction from milk MIR spectra is suitable for classifying animals according to their $\mathrm{CH}_{4}$ emission. However, to our knowledge, the prediction has not yet been tested by selecting cows according to their MIR $\mathrm{CH}_{4}$ phenotype and using actual measurements to confirm the between-animal and between-group differences. This validation can be realized by applying one of the established $\mathrm{CH}_{4}$ measurement methods, ideally under varying feeding conditions to exclude confounding with nutrition. Through use of the GreenFeed (GF) system, even grazing cows can be included (Hristov et al., 2015). This system analyzes respiration gas exchange in individual cows during their voluntary visits to a mobile feeding station. Rischewski et al. (2017) showed that it is possible to identify the cows with extremes of emissions (highest and lowest) using the GF system and RC.

Based on these considerations, our goals in the present study were to determine (1) the extent to which MIR estimates can be confirmed by GF measurements, (2) the persistence of the difference of groups of presumed low- and high-emitting cows, and (3) whether this categorization by $\mathrm{MeP}$ is also suitable for establishing differences in $\mathrm{CH}_{4}$ emission intensity (MeI; $\mathrm{g} / \mathrm{kg}$ of ECM), a trait that is much more important for sustainable milk production than absolute emissions per cow. In addition, we determined DMI, eating behavior, and ruminal fluid characteristics to better describe categorical differences.

\section{MATERIALS AND METHODS}

\section{Animals and Management}

The experiment was conducted at Agroscope (Posieux, Switzerland) from July to December 2016. The protocol complied with Swiss legislation for animal welfare and was approved by the Animal Care Committee of the Canton Fribourg, Fribourg, Switzerland (license no. 2016_17_FR). Twenty multiparous lactating Holstein Friesian cows were used. At the start of the experiment, the cows had $2.89 \pm 1.41$ parities (mean $\pm \mathrm{SD}$ ), weighed $641 \pm 36 \mathrm{~kg}$, produced $35.4 \pm 2.8 \mathrm{~kg}$ of milk/d, and were 76 DIM (range from 54 to $115 \mathrm{~d}$ ).

From July to the end of October, cows grazed as a single herd on pasture. The pasture sward consisted mainly of grasses $[76 \pm 10 \%$; English ryegrass (Lolium perenne) and smooth meadow-grass (Poa pratensis)], with some legumes $[16 \pm 8 \%$; white clover (Trifolium repens) and red clover (Trifolium pratense)] and herbs $[8 \pm 14 \%$; common dandelion (Taraxacum officinale)]. The cows grazed in a rotational system daily from 0800 to $1400 \mathrm{~h}$ and from 1800 to $0430 \mathrm{~h}$. In the time between, the cows were kept in a freestall barn and were milked starting at 0450 and $1550 \mathrm{~h}$. Paddock sizes were determined by assessments of herbage DM on offer $4 \mathrm{~cm}$ above ground, and they were changed about every third day based on a target postgrazing sward height of $4 \mathrm{~cm}$ measured using an electronic rising plate meter (Jenquip, Feilding, New Zealand). To determine herbage DM on offer, samples per paddock were collected with a bar mower, weighed, and analyzed for DM. The average pregrazing sward heights realized were $7.43 \pm 1.56 \mathrm{~cm}$, corresponding to $1.6 \pm 0.5 \mathrm{t}$ of $\mathrm{DM} /$ ha. During the first 2 mo on pasture (July and August), cows received an energy concentrate (Table 1) in transponder feeding stations (Insentec B.V., Marknesse, the Netherlands), depending on the individual milk yield, to meet the requirements for maintenance and milk yield (Agroscope, 2019a). During the last 2 mo on pasture (September and October), the cows received no concentrate.

In the last 2 mo of the experiment (November and December), the cows were kept exclusively in the freestall barn (indoors) and milked at the regular times. During the first 2 wk of this period, they received a mixed ration, including corn silage, $32.3 \%$; grass silage, $27.1 \%$; alfalfa silage, $14.1 \%$; hay, $18.5 \%$; soybean meal, $6 \%$; and an energy concentrate, $2.1 \%$. Afterward, until the end of December, they received a diet composed of corn silage, $39.2 \pm 2.4 \%$; grass silage, $27.4 \pm 1.2 \%$; alfalfa silage, $13.6 \pm 2.5 \%$; hay, $13.2 \pm 2.5 \%$; and soybean meal, $6.6 \pm 0.2 \%$ (TMR; indoor feeding). Fresh 
water, a vitaminized mineral mixture, and $\mathrm{NaCl}$ were available at all times.

\section{Estimation and Measurement of $\mathrm{CH}_{4}$ Emissions}

Estimation from Milk MIR Spectra. From July to December 2016, individual milk samples were collected from the 20 experimental cows once per week and daily during 2-weekly intensive collection periods in early August and early October. Samples from July were used to categorize cows for their daily MeP. Samples were conserved with Bronopol Broad Spectrum Microtabs (Gerber Instruments AG, Effretikon, Switzerland). For the weekly milk samples, the evening and morning samples were pooled according to their respective milk yield. The milk MIR spectra were determined from these samples using Fourier transform infrared spectrophotometry (MilkoScan FT6000, Foss Electric, Hillerød, Denmark). The spectra were harmonized into a common standardized format following the procedure described in Grelet et al. (2015). As described by Vanlierde et al. (2016), the Mahalanobis distance $(\mathrm{GH})$ was used to discriminate and remove experimental milk spectra that were considered too different from spectra used for the calibration process (with $\mathrm{GH}>3$ ). Only $0.5 \%$ of the data were removed according to this criterion. The $\mathrm{MeP}$ was predicted from these spectra by using a modified partial least-squares regression to develop a modified DIM-dependent $\mathrm{MeP}$ prediction equation (Vanlierde et al., 2016). The $\mathrm{CH}_{4}$ prediction equation applied in this study differs from the previ- ously published versions and should be more robust due to the larger variability included in the calibration. The equation was developed and calibrated from 1,089 $\mathrm{CH}_{4}$ measurements using either the $\mathrm{SF}_{6}$ tracer technique or RC on 299 cows, including 138 measurements from 57 Swiss cows (40 Brown Swiss, 9 Holstein, and 8 Red Holstein). This approach ensured that part of local variability was included in the prediction model. The equation for calibration is characterized by a standard error (SE) of calibration (SEC) of $58 \mathrm{~g} / \mathrm{d}$ and an $\mathrm{R}^{2} \mathrm{c}$ (where $\mathrm{c}=$ calibration) of 0.68 . For cross validation, $\mathrm{R}^{2} \mathrm{cv}$ was 0.64 and the standard error of cross validation $(\mathrm{SECV})$ was $61 \mathrm{~g} / \mathrm{d}$. The data set obtained from the entire experimental period (6 mo) had a mean $\mathrm{MeP}$ of $419 \pm 43.5(286-546) \mathrm{g} / \mathrm{d}$. Predictions $<150$ and $>950 \mathrm{~g} / \mathrm{d}$ were considered outliers and excluded from the statistical analysis (Vanlierde et al., 2016).

GreenFeed Measurements. The GF system (CLock Technology Inc., Rapid City, SD) consists of a mobile feeding station with integrated gas measurement equipment. Daily MeP estimations from the GF system are based on integrated measurements, considering ventilation airflow, temperature, humidity, and gas concentrations during the time the cow visited the station, and values are delimited by detection of head proximity inside the sampling hood (Hristov et al., 2015). In the present experiment, cows were allowed a maximum of 6 visits to the station over a day, 1 visit per 3 -h time slot, and encouraged to stay by releasing, per visit, up to 8 portions of $32 \mathrm{~g}$ of bait feed (pelleted dried whole corn plant; DM $90.6 \pm 0.52 \%$; NDF $32.6 \pm 1.58 \%$; ADF

Table 1. Composition (\% of DM) of feeds offered in the pasture (July to end of October) and indoor periods (November to December) as analyzed or calculated ( $\mathrm{n}=16$ each)

\begin{tabular}{|c|c|c|c|c|c|c|}
\hline \multirow[b]{2}{*}{ Item } & \multicolumn{2}{|c|}{ Pasture } & \multicolumn{2}{|c|}{ Energy concentrate } & \multicolumn{2}{|c|}{ TMR } \\
\hline & Mean & SD & Mean & $\mathrm{SD}$ & Mean & SD \\
\hline DM, $\%$ of original substance & 18.8 & 1.82 & 88.7 & 0.07 & 41.6 & 1.53 \\
\hline $\mathrm{CP}$ & 17.3 & 2.54 & 15.1 & 0.70 & 12.3 & 1.51 \\
\hline NDF & 42.8 & 2.32 & 10.8 & 0.37 & 40.5 & 2.81 \\
\hline $\mathrm{ADF}$ & 25.3 & 2.00 & 4.40 & 0.29 & 24.5 & 1.33 \\
\hline Water-soluble carbohydrates & 11.2 & 3.30 & 4.47 & 0.15 & 6.70 & 8.44 \\
\hline $\mathrm{Ca}$ & 0.75 & 0.10 & 0.78 & 0.05 & 0.51 & 0.15 \\
\hline $\mathrm{P}$ & 0.41 & 0.04 & 0.36 & 0.05 & 0.29 & 0.01 \\
\hline $\mathrm{Mg}$ & 0.23 & 0.02 & 0.11 & 0.01 & 0.16 & 0.02 \\
\hline $\mathrm{Na}$ & 0.03 & 0.01 & 0.19 & 0.02 & 0.01 & 0.01 \\
\hline K & 3.01 & 0.36 & 0.53 & 0.04 & 2.15 & 0.16 \\
\hline \multicolumn{7}{|l|}{ n-Alkanes, $\mathrm{mg} / \mathrm{kg}$ of DM } \\
\hline $\mathrm{C}_{32}$ & 5.54 & 0.85 & - & - & - & - \\
\hline $\mathrm{C}_{33}$ & 89.1 & 13.6 & - & - & - & - \\
\hline \multicolumn{7}{|l|}{ Calculated, ${ }^{1}$ per $\mathrm{kg}$ of DM } \\
\hline $\mathrm{NE}_{\mathrm{L}}, \mathrm{MJ}$ & 6.13 & 0.25 & 7.02 & 0.16 & 6.36 & 0.11 \\
\hline $\mathrm{APD},{ }^{2} \mathrm{~g}$ & 104 & 6 & 109 & 4 & 102 & 10 \\
\hline
\end{tabular}

\footnotetext{
${ }^{1}$ According to Agroscope (2019a).

${ }^{2}$ Absorbable protein at the duodenum when rumen fermentable energy is limiting microbial protein synthesis in the rumen.
} 
$17.3 \pm 0.95 \%$; CP $8.75 \pm 1.98 \%$; and water-soluble carbohydrates $7.45 \pm 0.79 \%$ ) at 20 -s intervals. The average number of visits per day was $2.52 \pm 0.42$, and the total bait feed intake per cow ranged between 538 and $742 \mathrm{~g} / \mathrm{d}$. This procedure was found to be adequate to keep the animals eating, exhaling, and eructing in the proximity of the air collection site of the GF device for enough time to allow a valid measurement. Air flow rate was 20 to $40 \mathrm{~L} / \mathrm{s}$. Air was filtered, quantified, and subsampled for analysis of concentrations of $\mathrm{CH}_{4}$ and $\mathrm{CO}_{2}$ by 2 nondispersive infrared sensors. The filter needs to be cleaned regularly, which was done every 2 wk in the present experiment, as proposed by Waghorn et al. (2018). The analyzers were calibrated daily around milking time, when the cows were not in the proximity of the device, with a zero gas (pure $\mathrm{N}_{2}$ ) and a span gas containing $5,000 \mathrm{ppm}$ of $\mathrm{CO}_{2}$ and $500 \mathrm{ppm}$ of $\mathrm{CH}_{4}$ per liter. The $\mathrm{CO}_{2}$ recovery was determined monthly by repeatedly releasing weighed amounts of $\mathrm{CO}_{2}$ into the unit's manifold, an approach that yielded recoveries of $97 \pm 2 \%$. The method for calculating MeP from the data obtained per visit and per day is described in Huhtanen et al. (2015). The MeP data derived from the GF system were first averaged for each hour of the day to account for variations in the distribution of visits over the day. Subsequently, data were averaged over 7 , 14 , and $28 \mathrm{~d}$. In the grazing season, 1 GF unit was set up on the paddock next to the water trough. Another GF unit was arranged in a cubicle in the freestall barn. With 2 devices, the cows could access the GF at any time except during milking. During the indoor period, a GF unit was placed in the barn.

\section{Data Recording and Sampling for Determining Additional Variables}

Milk yield was recorded automatically (Pulsameter 2, SAC; A. Bertschy AG, Guschelmuth, Switzerland) at each milking, that is, twice daily in the milking parlor. The BW of the cows was measured automatically as they left the milking parlor. Herbage intake during $7 \mathrm{~d}$ was estimated individually in each of the 2 collection periods, using the alkane double-indicator technique (Mayes et al., 1986). Briefly, $6 \mathrm{~d}$ before the start and until the end of the collection period, the cows received a gelatin capsule using a balling gun (Capsula $\mathrm{GmbH}$, Ratingen, Germany, HGK 17-60 sl) twice daily. The capsule contained $0.5 \mathrm{~g}$ of the alkane $\mathrm{C}_{32} \mathrm{H}_{66}$ applied on dried fruit pomace as carrier. During the collection periods, $60 \mathrm{~g} / \mathrm{d}$ of individual feces were collected between 0600 and $0700 \mathrm{~h}$ from either spontaneous or stimulated defecation. Samples were frozen at $-20^{\circ} \mathrm{C}$ and later pooled per period per cow. Herbage samples were cut using a battery grass shearer (Gardena, Husqvarna Schweiz AG, Mägenwil, Switzerland) on the same $7 \mathrm{~d}$, in the morning $(0800 \mathrm{~h})$ and evening $(1800 \mathrm{~h})$ after turnout to pasture by following the cows, as described by Graf et al. (2005). Samples were frozen at $-20^{\circ} \mathrm{C}$. The single components of the diet fed in the barn were collected separately and analyzed once per week in the indoor period. Eating and ruminating behavior was recorded daily per cow across $6 \mathrm{~d}$ in each of the $2 \mathrm{col}-$ lection periods using RumiWatch halters (Itin + Hoch GmbH, Liestal, Switzerland) (Rombach et al., 2018). Ruminal fluid was collected twice per sampling period in the morning directly after milking, using a stomach tube and manual pump (SELEKT Pump and Collector, Quidee GmbH, Homberg, Germany). Duplicate 10-mL samples were obtained. One sample was mixed with trichloroacetic acid for ammonia analysis. For VFA analysis, sulfuric acid was added. Samples were stored at $-20^{\circ} \mathrm{C}$ until analysis.

\section{Laboratory Analyses}

Diet components and fecal samples were lyophilized and milled through a $1.0-\mathrm{mm}$ screen (Brabender mill with titanium blades, Brabender, Duisburg, Germany). In these samples, DM and ash contents were determined by drying for $3 \mathrm{~h}$ at $105^{\circ} \mathrm{C}$, with subsequent incineration at $550^{\circ} \mathrm{C}$ until reaching constant weight. Mineral residues in the ash were dissolved with nitric acid and analyzed for $\mathrm{Ca}, \mathrm{K}, \mathrm{Mg}$, $\mathrm{Na}$, and $\mathrm{P}$ with inductively coupled plasma optical emission spectrometry (ICPOES 7300 DV, PerkinElmer, Waltham, MA), based on European Standard EN 155510:2008. The contents of n-alkanes $\mathrm{C}_{32}$ and $\mathrm{C}_{33}$ were determined on a GC fitted with flame ionization detection (Agilent 6850, Agilent Technologies, Santa Clara, CA), as described by Thanner et al. (2014). The $\mathrm{N}$ content was analyzed using the Dumas method (AOAC International, 1995) on a C/N analyzer (Trumac CNS, Leco Instruments, St. Joseph, $\mathrm{MI})$. The $\mathrm{CP}$ was calculated as $6.25 \times \mathrm{N}$. The contents of NDF and ADF (procedures 2002.04 and 973.18 of AOAC International, 1995, respectively) of the forages were determined using a Fibertherm (Gerhardt GmbH, Königswinter, Germany). The NDF was assessed with the addition of heat-stable amylase and sodium sulfite. A correction for residual ash was done for both ADF and NDF. Water-soluble carbohydrate contents were determined following Hall et al. (1999). The ruminal VFA were analyzed using HPLC equipped with a refractive index detector (Shodex RI, Denko K.K., Minato, Japan) and a Nucleogel ION column (300 OA $300 \times$ 
7.8 mm, Macherey-Nagel, Düren, Germany). Ruminal ammonia was analyzed colorimetrically with test kit S 180 (bioMérieux, Geneva, Switzerland).

\section{Calculations and Statistical Analysis}

Calculations. Milk fat, protein, and lactose contents were from the same MIR spectra used for $\mathrm{CH}_{4}$ estimation. The ECM $(\mathrm{kg} / \mathrm{d})$ was calculated using the equation of Agroscope (2019a): milk $(\mathrm{kg} / \mathrm{d}) \times[0.38 \times$ fat $(\%)+0.24 \times$ protein $(\%)+0.17 \times$ lactose $(\%)] / 3.14$. The $\mathrm{NE}_{\mathrm{L}}$ was calculated for fresh herbage according to Swiss recommendations for ruminant nutrition (Agroscope, 2019a). For that, the OM digestibility was estimated using the regression suggested by Agroscope (2019a) for fresh herbage with unknown botanical composition. The absorbable protein at the duodenum (a way to calculate MP) was calculated for fresh herbage, according to Agroscope (2019a), as (0.093 × fermentable $\mathrm{OM}, \mathrm{g} / \mathrm{kg}$ of $\mathrm{DM})+\{\mathrm{CP}, \mathrm{g} / \mathrm{kg} \mathrm{DM} \times[1.11 \times$ $(1$ - degradability of $\mathrm{CP}, \% / 100)]\} \times($ AA digestibility, $\% / 100)$. Fermentable OM, degradability of CP, and digestibilities of AA were tabular values taken from Agroscope (2019b).

All statistical analyses were performed using the statistical software platform $\mathrm{R}$, version 3.3.1 (R Core Team, 2018).

Categorization of Cows by $\mathrm{CH}_{4}$ Emissions. The experimental herd of 20 cows was classified by the milk MIR MeP predictions of July, and individual cows were allocated to 2 groups with contrasting $\mathrm{MeP}$ and MeI. Based on 1 milk sample per cow per week, 4 MIR MeP predictions were averaged per cow. The averaged values were used in a linear model that was applied to $\mathrm{MeP}$ $\left(Y_{i j k l}\right)$, considering the fixed effects $\mathrm{BW}\left(\beta_{\mathrm{i}}=\right.$ regression coefficient), ECM yield $\left(\beta_{\mathrm{j}}\right)$, DIM $\left(\beta_{\mathrm{k}}\right)$, and NDF of the pasture $\left(\beta_{1}\right)$, with $\varepsilon_{\mathrm{ijkl}}$ as the random residual. Because each effect was significant $(P<0.05)$, all effects were retained in the model. Subsequently, the MeP values predicted by the described linear model were used to group the 20 dairy cows into 2 categories, low and high $(\mathrm{n}=10$ each $)$ :

$$
\begin{gathered}
\mathrm{Y}_{\mathrm{ijkl}}=\mu+\beta_{\mathrm{i}} \mathrm{BW}+\beta_{\mathrm{j}} \mathrm{ECM} \text { yield }+\beta_{\mathrm{k}} \mathrm{DIM} \\
+\beta_{\mathrm{l}} \mathrm{NDF}+\varepsilon_{\mathrm{ijkl}} .
\end{gathered}
$$

Creation of Subsets from $\mathrm{CH}_{4}$ Data Obtained from August to December. The MeP and MeI data derived from the MIR estimates and the GF system in the $5 \mathrm{mo}$ of the experiment were averaged for 7-, 14-, and 28-d periods to determine the amount of time required for reliable discrimination of groups, considering uncertainties of the individual measurements and, in the case of GF, the different number of visits to the device. Subsequently, these values were averaged over 7, 14, and $28 \mathrm{~d}$ across August to December for further statistical analysis. The MeP values outside of 150 to $800 \mathrm{~g} / \mathrm{d}(<150 \mathrm{~g} / \mathrm{d}=1.06 \%$ of all data; $>800 \mathrm{~g} / \mathrm{d}=$ $1.11 \%$ of all data) were discarded from the data set because they were beyond the range of values reported by others (Dorich et al., 2015). For calculating MeI, the ECM data corresponding to the respective times of determining the $\mathrm{MeP}$ averages were used.

Analysis of Persistence of $\mathrm{CH}_{4}$ Emission from Cow Categories. The persistence of a cow's allocation to the low or high category over time throughout the experiment was analyzed with a split-plot ANOVA (Gill, 1986), using the R package glm2 (Marschner and Donoghoe, 2018). The model included effects of $\mathrm{CH}_{4}$ emission category (low or high) using animal within category as the error term, the effects of period $(7,14$, or $28 \mathrm{~d}$ ), and the interaction category $\times$ period. The covariates used were BW, ECM (not for MeI), DIM, NDF content of the pasture and TMR, and feeding regimen (pasture, indoors). A similar split-plot analysis model was used to evaluate the persistence of $\mathrm{MeP}$ over the 2 feeding regimens, with feeding regimen used in place of period. For this purpose, the last 8 wk of grazing and the first $8 \mathrm{wk}$ of the indoor period were used to obtain a balanced data set, and the data were analyzed as described above, with averages over the 7-, $14-$, and 28-d periods. The covariates used additionally were BW, ECM (not for MeI), and DIM. Significant category $\times$ period or category $\times$ feeding regimen interactions indicate that categorization was not consistent over the experimental period or the 2 feeding regimens, even when category was significant.

Analysis of Differences Between Cows of the 2 Categories. A linear mixed model was used to evaluate the differences between animals in the low and high categories for all variables measured. For that purpose, the R-package nlme was used (Pinheiro et al., 2017). The model included category and period and their interaction as fixed effects and the individual animals as the random effect.

Regression, Repeatability, Concordance Correlation Coefficient, and Repeated-Measures Correlation Calculations. Linear regression between the $\mathrm{MeP}$ obtained from the GF (averaged over $7 \mathrm{~d}$ ) and predicted by means of the milk MIR spectra (averaged over $7 \mathrm{~d}$ ) were calculated using the $\mathrm{MeP}$ data fitted by the described generalized linear model. Finally, the adjusted repeatability of the 2 methods applied for assessing $\mathrm{MeP}$ was calculated using the $\mathrm{R}$ package $\mathrm{rptR}$ (Stoffel et al., 2018). The variance components were estimated by a linear mixed model in which BW, ECM, DIM, and feeding regimen were included as fixed ef- 
Table 2. Methane production $(\mathrm{g} / \mathrm{d}, \mathrm{MeP})$ and emission intensity $(\mathrm{g} / \mathrm{kg}$ of $\mathrm{ECM}, \mathrm{MeI})$ as estimated from milk mid-infrared (MIR) spectra or measured by GreenFeed (C-Lock Technology Inc., Rapid City, SD) in the first month (July) of data collection as well as BW, milk yield, DIM, concentrate and bait feed intake ( $\mathrm{kg}$ of DM /d) of cows categorized by MIR as low and high emitters $(n=10 \text { cows each })^{1}$

\begin{tabular}{lccccc}
\hline & \multicolumn{2}{c}{ Low emitters } & & \multicolumn{2}{c}{ High emitters } \\
\cline { 2 - 3 } \cline { 5 - 6 } Item & Mean & SD & & Mean & SD \\
\hline MeP & 395 & 20.2 & & 438 & 15.1 \\
MIR & 426 & 34.3 & & 478 & 39.4 \\
GreenFeed & & & & 15.3 & 1.00 \\
MeI & 12.6 & 1.41 & & 17.8 & 2.51 \\
MIR & 14.5 & 1.64 & & 617 & 38.3 \\
GreenFeed & 311 & 27.2 & & 29.3 & 2.02 \\
BW, kg & 30.4 & 4.02 & & 107 & 16.8 \\
ECM, kg/d & 97.4 & 10.5 & & & \\
DIM & 2.64 & 0.88 & & 2.63 & 0.88 \\
Concentrate intake & 0.57 & 0.22 & & 0.59 & 0.24 \\
Bait feed ${ }^{2}$ intake (GreenFeed) & & & & & \\
\hline A
\end{tabular}

${ }^{1}$ A linear model using BW, ECM yield, DIM, and NDF content of the diet as effects was used to divide the experimental herd into low and high $\mathrm{CH}_{4}$ emitters.

${ }^{2}$ Pelleted dried whole corn plant.

fects, with cow as the random effect. In addition, the concordance correlation (CCC) was calculated using the epiR package in R (Stevenson et al., 2019) to evaluate the concordance between the 2 applied models. The rmcorr package (Bakdash and Marusich, 2018) was used to calculate the repeated measures correlation of MIR and GF, which can be seen as a proxy for the genetic correlation (Sorg et al., 2018). Moreover, the difference in the means of the MIR estimates and the GF measurements was divided by the mean of the GF measurements. The resultant percentage indicated the accuracy of the MIR results in comparison with GF results and is hereinafter referred to as the relative difference.

Presentation of Results. Effects were considered statistically significant at $P<0.05$, and $P<0.10$ was considered as indicating a trend. In the tables, the overall least squares means of the categories and the $P$-values for the period effects, the emission category effects (see above), and their interaction are shown. In addition, the SE of the effects are shown.

\section{RESULTS}

\section{Diet Composition During Pasture and Indoor Feeding Periods}

The average diet composition of pasture and indoor feeding (TMR) periods indicated a $55 \%$ lower DM content in the first mentioned diet (Table 1). Contents of $\mathrm{CP}$ and water-soluble carbohydrates of the pasture diet were higher by 41 and $67 \%$, respectively, than those of the indoor diet in a comparison of pasture and offered TMR. Moreover, the contents of NDF and ADF were higher by 5.7 and $3.3 \%$, respectively, in pasture versus the indoor diet. The $\mathrm{Ca}, \mathrm{P}, \mathrm{Mg}, \mathrm{Na}$, and $\mathrm{K}$ contents were slightly higher in the pasture diet than in the TMR feed indoors.

\section{Characterization of Cows Allocated to Categories at the Time of Selection}

The 10 cows categorized as low emitters had 10 and $11 \%$ lower initial MeP levels than cows in the high emission category based on MIR and GF measurements, respectively (Table 2). The corresponding values for MeI were 18 and 18\% (based on ECM per day and per week, respectively). On average, the low emitters were initially $1 \%$ lighter than the high emitters, produced $4 \%$ more ECM, and were $10 \mathrm{~d}$ earlier in lactation. Moreover, cows in both categories ingested on average similar amounts of an energy concentrate and of bait feed at the GF.

\section{Relationship Between Predicted and Measured $\mathrm{CH}_{4}$ Emission of Individual Cows}

Weak but significant relationships (linear regressions) were found between the MeP predicted by milk MIR spectra and the MeP measured by the GF device, using data from 7-d periods (results presented in Figure 1). The CCC between MIR and the GF measurements concerning $\mathrm{MeP}$ increased numerically with increasing duration of the measurement period $(P>0.05)$. 


\section{7-day periods}

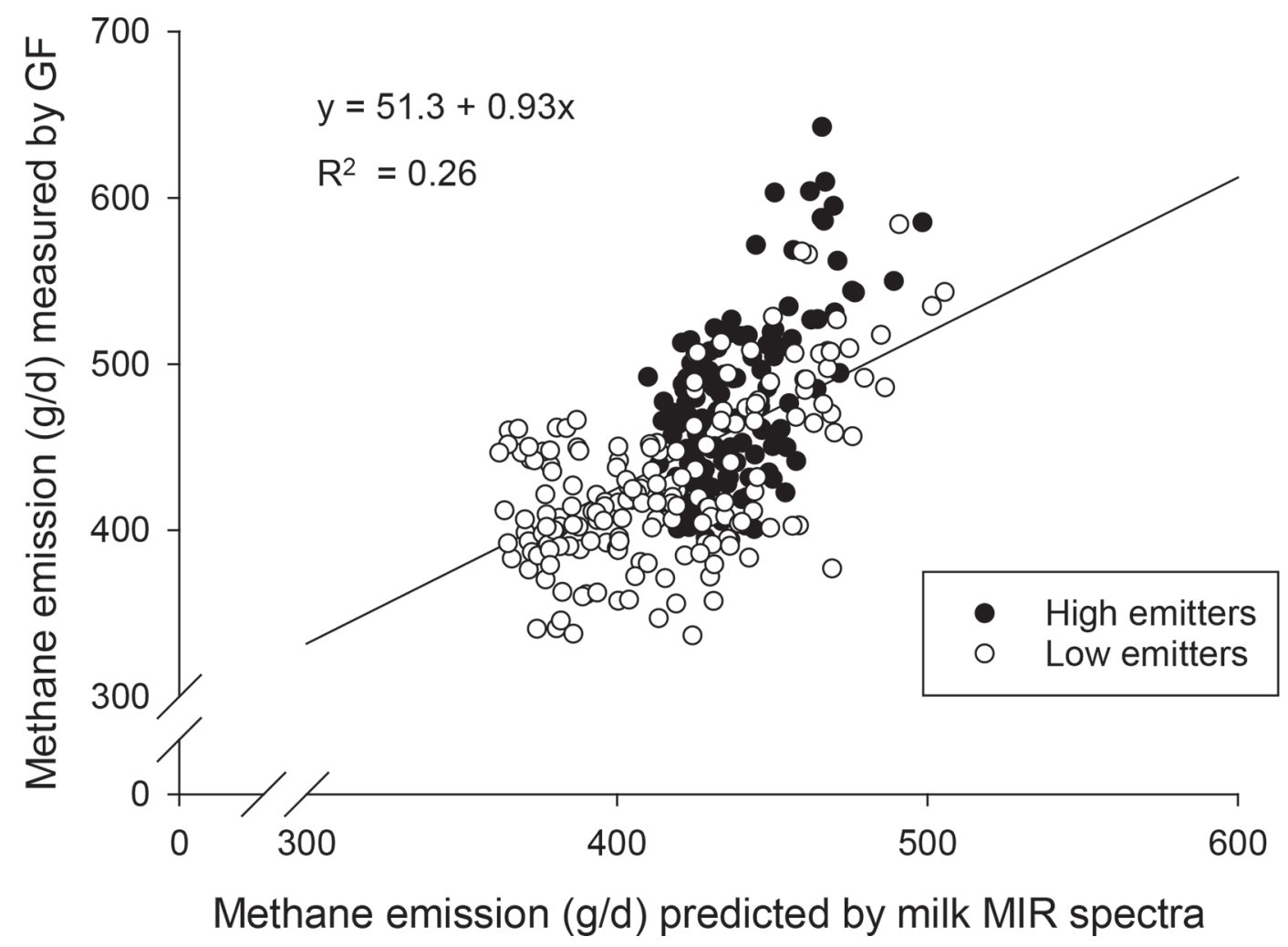

Figure 1. Relationship between methane production (g/d) measured by the GreenFeed (GF; C-Lock Technology Inc., Rapid City, SD) system and predicted by the milk mid-infrared (MIR) spectra in cows characterized as low (white circle, $\mathrm{N}$ cows $=10, \mathrm{n}$ data $=200$ ) and high $($ dark circle, $\mathrm{N}$ cows $=10, \mathrm{n}$ data $=200)$ methane emitters. Data were predicted by a generalized linear model including BW, ECM yield, feeding regimen, DIM, and dietary NDF content as covariates. $\mathrm{R}^{2}(0.26 ; P<0.01)$; slope $(0.93 ; P<0.001)$.

\section{Evolution of the Differences Between Emission Categories over Time}

The difference between low- and high-emitting cows in $\mathrm{MeP}$, as estimated from milk MIR spectra, clearly persisted over time (Figure 2, left). The differentiation was also apparent in MeP measured by GF (Figure 2 , right) during 5 mo of data collection. Also, when calculated for each individual month of the experiment, the difference in $\mathrm{MeP}_{\mathrm{MIR}}$ found between low- and highemitting cows $(P<0.01)$ persisted and did not change with time $(P>0.10$; Table 3$)$. No interaction $(P>$ $0.10)$ was found between category and month.

With regard to 7-, 14-, and 28-d periods across the 20 wk of the experiment (Table 4), the low-emitting cows had a lower $(P<0.05$ to $P<0.001) \mathrm{MeP}$ than the high-emitting cows, according to both MIR and GF, respectively, although values also differed $(P<0.05$ to
$P<0.001$ ) between the 7- and 14-d periods (Table 4). No interaction $(P>0.10)$ was found between category and period. In MeI, a category difference was observed when applying 7 -d $(P<0.01)$, 14-d $(P<0.05)$, and 28 -d periods $(P<0.10)$; with MIR and with GF, a difference between the categories $(P<0.05$ to $P<$ $0.001)$ was also apparent. Period effects occurred for all periods with MIR and GF, except for 7-d periods with GF. A category $\times$ period interaction $(P<0.05$ to $P<$ 0.01 ) occurred with GF and MIR, using 7 -d and 14-d periods.

When using feeding regimen instead of period as the main factor in the ANOVA, the category differences found were, in many cases, the same (Table 5). In contrast to the results of the period model, no category differences in MeI in the 28-d period were found with MIR $(P>0.10)$ and GF $(P>0.10)$ measurements. Feeding regimen $(P<0.001)$ affected the $\mathrm{MeP}$ in the 7 - $\mathrm{d}$ and 
14-d periods based on MIR. With GF, only feeding regimen in the 7 -d period $(P<0.05)$ was found to affect $\mathrm{MeP}$. An effect on MeI from the feeding regimen in the 7 -d period $(P>0.01)$ was only found with MIR. Interactions between category and feeding regimen were not found in MeP, whereas interactions affected MeI at all occasions $(P<0.05$ to $P<0.001)$, except with MIR and GF in the 28-d period.

\section{Repeatability of the Differences Between Emission Categories}

The MeP differences were repeatable $(P<0.001)$ when calculated for $\mathrm{CH}_{4}$ values averaged over any period, 7, 14, or 28 d (Table 6). Repeatability increased numerically for the MIR estimates when the period was extended from 7 and $14 \mathrm{~d}$ to $28 \mathrm{~d}$. For the GF measure-
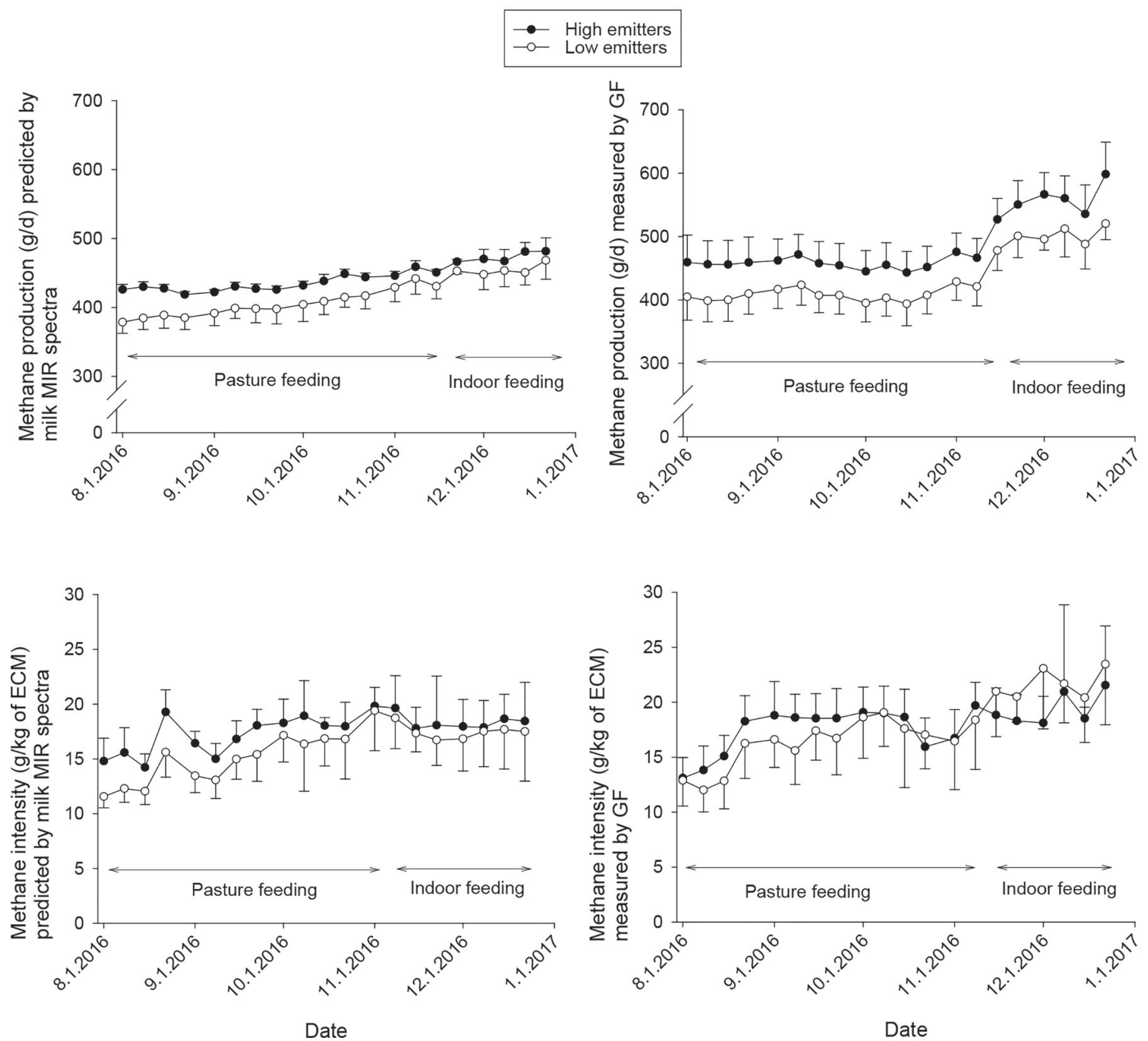

Figure 2. Pattern of methane production (top) and emission intensity (bottom) (7-d averages) as estimated by milk mid-infrared spectra (MIR; left) and measured by the GreenFeed system (GF, right; C-Lock Technology Inc., Rapid City, SD) across the entire study (August to December; month.day.year format) in cows categorized as low emitters (white circle; $\mathrm{n}=10$ ) or as high emitters (dark circle; $\mathrm{n}=10)$ of methane based on July milk MIR spectra. Error bars indicate SD. 
Table 3. Mean ${ }^{1}$ methane production $(\mathrm{g} / \mathrm{d})$ during the 5 months $(\mathrm{M})$ of the experiment estimated by mid-infrared (MIR) spectra ${ }^{2}$ in cows categorized (C) as low or high emitters by MIR estimates made before the experiment (in July) (n = 10 cows each)

\begin{tabular}{|c|c|c|c|c|c|c|c|c|c|}
\hline Item & \multicolumn{5}{|c|}{ Month } & Mean & \multicolumn{3}{|c|}{ SE and significance } \\
\hline Low emitters & 430 & 382 & 512 & 683 & 431 & 489 & $4.6^{* *}$ & $10.3^{\mathrm{NS}}$ & $15.3^{\mathrm{NS}}$ \\
\hline
\end{tabular}

ments, a slight increase in repeatability was found from 7 to $14 \mathrm{~d}$, but a decrease occurred by 28 d. Extending the period only slightly reduced the between-animal coefficient of variation (CV) in both methods. The repeated-measures correlation for the 2 methods was low $(P>0.05)$ and similar for the 3 different measurement periods. The relative difference increased from 0.22 to $4.77 \%$

\section{Other Variables Measured on Pasture in Low and High $\mathrm{CH}_{4}$ Emitters}

On average, of the 2 collection periods in the grazing season, low- and high-emitting cows did not differ $(P$ $>0.10$ ) in DMI and ruminating time (Table 7 ). The low-emitting cows spent less time eating than the highemitting cows $(P<0.05)$. Total VFA concentration and the proportion of butyrate of total VFA in the ruminal fluid were similar $(P>0.10)$ between the 2 categories of cows as well. However, the acetate proportion tended to be higher $(P<0.10)$, the propionate proportion lower $(P<0.10)$, and the acetate-to-propionate ratio higher
$(P<0.10)$ for the high emitters compared with the low emitters. Ruminal ammonia concentrations $(P>0.10)$ did not differ between the 2 groups (Table 7 ).

\section{DISCUSSION}

\section{Methods Used for Assessments of $\mathrm{CH}_{4}$ Emission}

Estimating $\mathrm{CH}_{4}$ Emissions with Milk MIR Spectra. Several reports have highlighted the suitability of milk MIR spectra from individual cows to estimate MeP (Kandel et al., 2017; Vanlierde et al., 2015, 2016). In contrast, Shetty et al. (2017) showed that this method was not reproducible under commercial conditions when MeP was concomitantly measured with the sniffer method. For the present experiment, we used an updated version of the prediction equation of Vanlierde et al. (2016), which also included data from 57 Swiss cows fed Swiss-type diets. Soyeurt et al. (2011) showed that milk MIR spectra are useful in predicting milk fatty acid composition. The milk fatty acid profile is at least partly determined by the products of ruminal fermentation and variations thereof (Bernard et al., 2008).

Table 4. Methane production ${ }^{1}(\mathrm{~g} / \mathrm{d}, \mathrm{MeP})$ and emission intensity ${ }^{2}$ ( $\mathrm{g} / \mathrm{kg}$ of ECM, MeI) estimated by milk mid-infrared (MIR) spectra and measured by GreenFeed (GF; C-Lock Technology Inc., Rapid City, SD) for $140 \mathrm{~d}$ and averaged over 7-, 14-, and 28-d periods (P) in cows categorized (C) as low or high emitters (based on MIR before the experiment)

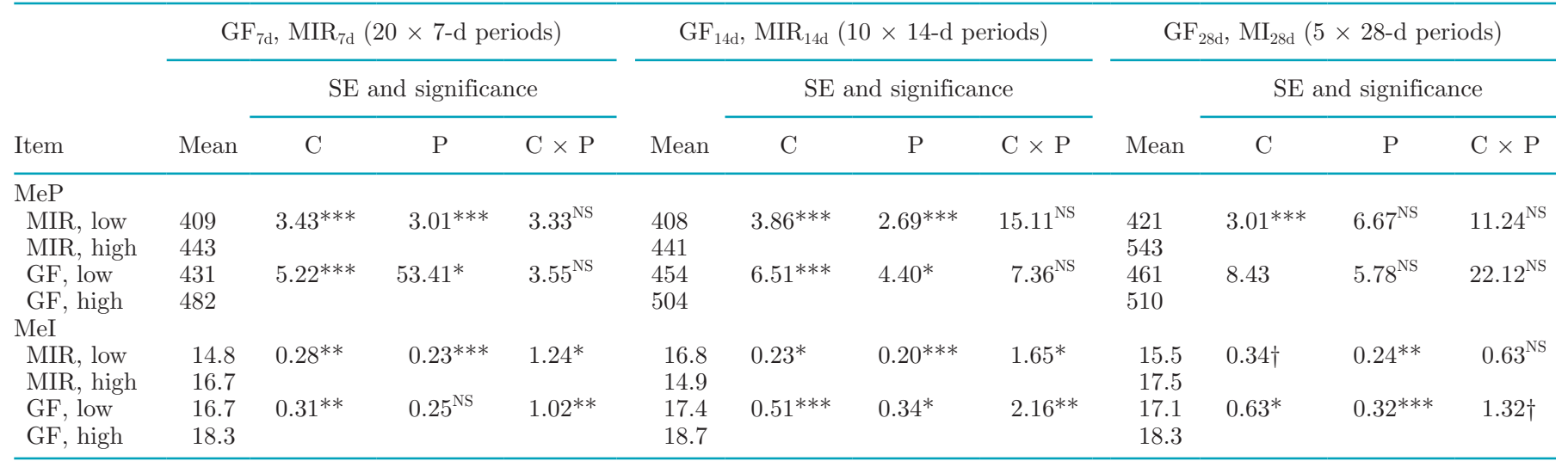

${ }^{1}$ Adjusted means (including BW, feeding regimen, ECM yield, DIM, and dietary NDF content as covariates).

${ }^{2}$ Adjusted means (including BW, feeding regimen, DIM, and dietary NDF content as covariates).

$\dagger P<0.10 ;{ }^{*} P<0.05 ;{ }^{* *} P<0.01 ; * * * P<0.001 ;{ }^{\text {NS }} P>0.05$. 
Table 5. Effect of feeding regimen (F; pasture vs. indoor feeding) on methane production ${ }^{1}(\mathrm{~g} / \mathrm{d}, \mathrm{MeP})$ and emission intensity $^{2}(\mathrm{~g} / \mathrm{kg}$ of ECM, MeI) estimated by milk mid-infrared (MIR) spectra and measured by GreenFeed (GF; C-Lock Technology Inc., Rapid City, SD) for 140 d averaged over 7-, 14-, and 28-d periods in cows categorized (C) as low and high emitters (based on MIR before the experiment)

\begin{tabular}{|c|c|c|c|c|c|c|c|c|c|c|c|c|}
\hline \multirow[b]{3}{*}{ Item } & \multicolumn{4}{|c|}{$\mathrm{GF}_{7 \mathrm{~d}}, \mathrm{MIR}_{7 \mathrm{~d}}(7-\mathrm{d}$ periods $)$} & \multicolumn{4}{|c|}{$\mathrm{GF}_{14 \mathrm{~d}}, \mathrm{MIR}_{14 \mathrm{~d}}$ (14-d periods) } & \multicolumn{4}{|c|}{$\mathrm{GF}_{28 \mathrm{~d}}, \mathrm{MIR}_{28 \mathrm{~d}}$ (28-d periods) } \\
\hline & \multirow[b]{2}{*}{ Mean } & \multicolumn{3}{|c|}{ SE and significance } & \multirow[b]{2}{*}{ Mean } & \multicolumn{3}{|c|}{ SE and significance } & \multirow[b]{2}{*}{ Mean } & \multicolumn{3}{|c|}{ SE and significance } \\
\hline & & $\mathrm{C}$ & $\mathrm{F}$ & $\mathrm{C} \times \mathrm{F}$ & & $\mathrm{C}$ & $\mathrm{F}$ & $\mathrm{C} \times \mathrm{F}$ & & $\mathrm{C}$ & $\mathrm{F}$ & $\mathrm{C} \times \mathrm{F}$ \\
\hline \multicolumn{13}{|l|}{$\mathrm{MeP}$} \\
\hline MIR, low & 418 & $3.71^{* * *}$ & $4.71^{* * *}$ & $6.33^{\mathrm{NS}}$ & 433 & $5.29^{* * *}$ & $7.13^{\text {*** }}$ & $8.93^{\mathrm{NS}}$ & 419 & $10.1^{* * *}$ & $10.5^{\mathrm{NS}}$ & $13.6^{\mathrm{NS}}$ \\
\hline MIR, high & 446 & & & & 458 & & & & 447 & & & \\
\hline \multicolumn{13}{|l|}{ MeI } \\
\hline MIR, low & 16.6 & $0.34^{*}$ & $0.65^{* *}$ & $0.55^{*}$ & 17.2 & $0.44 \dagger$ & $0.60^{\mathrm{NS}}$ & $0.64 \dagger$ & 16.3 & $0.68^{\mathrm{NS}}$ & $0.78^{\mathrm{NS}}$ & $1.03^{\mathrm{NS}}$ \\
\hline MIR, high & 18.3 & & & & 18.8 & & & & 18.1 & & & \\
\hline $\mathrm{GF}$, low & 18.5 & $0.25^{* * *}$ & $0.38^{\mathrm{NS}}$ & $0.51^{* *}$ & 18.1 & $0.61^{* * *}$ & $0.56^{\mathrm{NS}}$ & $0.82^{* * *}$ & 19.8 & $0.75^{\mathrm{NS}}$ & $1.04^{\mathrm{NS}}$ & $0.97^{\mathrm{NS}}$ \\
\hline GF, high & 20.4 & & & & 20.4 & & & & 20.2 & & & \\
\hline
\end{tabular}

${ }^{1}$ Adjusted means (including BW, ECM yield, DIM, and dietary NDF content as covariates).

${ }^{2}$ Adjusted means (including BW, DIM, and dietary NDF content as covariates).

$\dagger P<0.10 ;{ }^{*} P<0.05 ;{ }^{* *} P<0.01 ;{ }^{* * *} P<0.001 ;{ }^{\mathrm{NS}} P>0.05$.

The present predictions varied from 286 to $546 \mathrm{~g} / \mathrm{d}$ for MeP and from 9.41 to $27.7 \mathrm{~g} / \mathrm{kg}$ of ECM for MeI, which were within the ranges reported from measurements in dairy cows (e.g., Garnsworthy et al., 2012; Grandl et al., 2016). As pointed out by van Gastelen and Dijkstra (2016), MIR spectra alone may not be sufficient for a reliable prediction, but the predictive power could increase by integrating information on parity, DIM, and feed composition. Meanwhile, in improving the equation, Vanlierde et al. $(2016,2018)$ had already included DIM by making the coefficient of the calibration equation dependent on the lactation stage.

Usefulness of the GF Device as a Reference Method. The GF device was chosen as the method for gathering data to validate MIR estimates. Since its introduction, the GF device has been used frequently, but some limitations have been observed. The quality of GF measurements depends largely on sufficient frequency of voluntary visits to the device by each animal (Hristov et al., 2016; Waghorn et al., 2016). Visits need to be evenly distributed across the day (Hammond et al., 2016) because MeP has a clear diurnal pattern related to the pattern of DMI, which varies between feeding regimens (Oddy et al., 2018). The cows in our study visited the device on average $2.52 \pm 0.43$ times per day for $3.46 \pm 0.65 \mathrm{~min}$ per visit. Hammond et al. (2015) found similar frequencies, while Huhtanen et al. (2015) reported a slightly higher frequency. To take into account the effects of timing of visits and avoid bias caused by uneven distribution of the visits over the day, we first averaged the values per time of day and then averaged the resulting values over the 7-, 14-, and

Table 6. Repeatability, CV between animals, the relative difference (\%), and correlations estimated with milk mid-infrared (MIR) spectra and measured with GreenFeed (C-Lock Technology Inc., Rapid City, SD) for methane production $(\mathrm{g} / \mathrm{d})$ at different time points in the measurement period

\begin{tabular}{|c|c|c|c|}
\hline \multirow[b]{2}{*}{ Item } & \multicolumn{3}{|c|}{ Period length, d } \\
\hline & 7 & 14 & 28 \\
\hline \multicolumn{4}{|l|}{ Repeatability } \\
\hline MIR & $0.34^{* * *}$ & $0.39^{* * *}$ & $0.55^{* * *}$ \\
\hline GreenFeed & $0.64^{* * *}$ & $0.68^{* * *}$ & $0.59^{* * *}$ \\
\hline \multicolumn{4}{|l|}{ Between-animal CV, \% } \\
\hline MIR & 11.1 & 9.75 & 9.27 \\
\hline GreenFeed & 14.1 & 14.0 & 12.6 \\
\hline Relative difference, ${ }^{1} \%$ & 0.22 & 3.09 & 4.77 \\
\hline \multicolumn{4}{|l|}{ Correlations } \\
\hline Concordance correlation coefficient & $0.15^{\mathrm{NS}}$ & $0.18^{\mathrm{NS}}$ & $0.19^{\mathrm{NS}}$ \\
\hline Repeated-measures correlation & $0.11^{\mathrm{NS}}$ & $0.12^{\mathrm{NS}}$ & $0.12^{\mathrm{NS}}$ \\
\hline
\end{tabular}

${ }^{1}$ Difference in the means of the MIR estimates and the GreenFeed measurements divided by the mean of the GreenFeed measurements.

*** $P<0.001 ;{ }^{\mathrm{NS}} P>0.05$. 
Table 7. Means and SE of intake, eating and rumination behavior, as well as ruminal fluid characteristics during 2 collection periods in the grazing season in cows categorized as low and high emitters estimated by milk mid-infrared (MIR) spectra made before the collection periods

\begin{tabular}{|c|c|c|c|c|c|c|}
\hline \multirow[b]{2}{*}{ Item } & \multicolumn{2}{|c|}{ Category } & \multirow[b]{2}{*}{$\mathrm{SE}$} & \multicolumn{3}{|c|}{$P$-value } \\
\hline & $\begin{array}{c}\text { Low } \\
\text { emitters }\end{array}$ & $\begin{array}{l}\text { High } \\
\text { emitters }\end{array}$ & & Category & Period & $\begin{array}{l}\text { Category } \\
\times \text { Period }\end{array}$ \\
\hline DMI, kg/d & 16.9 & 17.0 & 1.32 & 0.93 & 0.98 & 0.68 \\
\hline Eating time, $\min / \mathrm{d}$ & 620 & 671 & 25.5 & 0.05 & 0.49 & 0.57 \\
\hline Ruminating time, min/d & 414 & 386 & 13.7 & 0.14 & 0.02 & 0.65 \\
\hline \multicolumn{7}{|l|}{ Ruminal fluid characteristics } \\
\hline $\mathrm{VFA}, \mathrm{mmol} / \mathrm{L}$ & 91.2 & 90.0 & 2.18 & 0.71 & 0.03 & 0.36 \\
\hline Acetate, molar $\%$ of VFA & 78.0 & 78.8 & 0.45 & 0.07 & $<0.001$ & 0.15 \\
\hline Propionate, molar $\%$ of VFA & 19.3 & 17.1 & 0.413 & 0.08 & 0.07 & 0.87 \\
\hline Butyrate, molar \% of VFA & 12.7 & 12.6 & 0.015 & 0.52 & $<0.001$ & $<0.01$ \\
\hline Acetate/propionate & 3.63 & 3.86 & 0.114 & 0.09 & 0.01 & 0.91 \\
\hline Ammonia, mmol/L & 6.54 & 7.23 & 0.065 & 0.12 & $<0.001$ & 0.90 \\
\hline
\end{tabular}

28-d periods, respectively. Validation of GF measurements by other methods showed an acceptable level of agreement among measured $\mathrm{CH}_{4}$ emissions. Hammond et al. (2015) found a moderate relationship $\left(\mathrm{R}^{2}=0.40\right)$ between measurements obtained with GF and with the $\mathrm{SF}_{6}$ tracer technique. Rischewski et al. (2017) ranked the same cows as high and low $\mathrm{CH}_{4}$ emitters by using GF and RC.

\section{Accuracy of MIR Estimates Based on GF Measurements for Reference}

Quality of MIR Estimates as Determined by Comparison with GF Data. The MIR-based MeP predictions from data obtained using the $\mathrm{SF}_{6}$ tracer method showed a good correlation to a reference data set (calibration $\mathrm{R}^{2}=0.75$ ). When we compared predicted MeP to RC-based measurement from an external data set (Vanlierde et al., 2015), we found a moderate correlation $(\mathrm{r}=0.48)$. Based on the current equation using the $\mathrm{SF}_{6}$ method and $\mathrm{RC}$, the cross-validation $\mathrm{SE}$ was $61 \mathrm{~g} / \mathrm{d}$. For an RC-based prediction, the cross-validation $\mathrm{SE}$ was $47 \mathrm{~g} / \mathrm{d}$, and for an $\mathrm{SF}_{6}$-based prediction, it was $70 \mathrm{~g} / \mathrm{d}$ (Vanlierde et al., 2018). As pointed out by Vanlierde and colleagues, a lower cross-validation $\mathrm{SE}$ shows that the equation is closer to actual values, indicating that the current study improves on the $\mathrm{SF}_{6}{ }^{-}$ based equation. However, using data (e.g., breed, diet, management) that are more reflective of the variability of conditions in Switzerland might increase the suitability of the equation. In addition, the GF measurements (spot measurements of approximately 3-4 min) may be influenced by the number of visits or their distribution over a 24-h period (Hristov et al., 2016). The $\mathrm{CO}_{2}$ recovery rate determined by the GF device was $97.0 \pm$ $2 \%$ on average, which suggests that the measurement technique is accurate. The MIR and GF methods both have sources of errors that possibly affected the $\mathrm{CH}_{4}$ values obtained. To our knowledge, we are the first to concurrently use GF and milk MIR to determine MeP in the same individual dairy cows. The resulting relationship between findings from the 2 methods turned out to be weak, suggesting that predicting $\mathrm{MeP}$ with milk MIR spectra, despite applying several adjustments such as DIM, might be insufficiently accurate to identify animals that are high and low $\mathrm{CH}_{4}$ emitters. Moreover, the relative differences indicate that the accuracy of the MIR estimations became worse as the period was extended from 7 to $28 \mathrm{~d}$. However, getting reliable genetic correlations between different $\mathrm{MeP}$ estimates is also necessary to check if genetic rankings of animals based on these traits would be similar.

Repeatability of Measurements, Between-Cow Variation, and $C C C$. In calculating repeatability of the $\mathrm{MeP}$ data obtained with the 2 methods, we took BW, ECM yield, DIM, and feeding regimen into account because they may affect $\mathrm{CH}_{4}$ production in dairy cows (Garnsworthy et al., 2012). Arbre et al. (2016) arbitrarily set repeatability to 0.7 to determine the optimum measurement period for $\mathrm{MeP}$, meaning that, under the current experimental conditions, 28-d periods with 1 sample (mixture of morning and evening milk) per week were not sufficient for MIR-based estimation. The highest repeatability in our study occurred with GF in 14-d measurement intervals and approached the 0.7 threshold of Arbre et al. (2016); however, high repeatability reflects high precision but not necessarily high accuracy of the data. Indicators such as betweenand within-cow variation should also be taken into account (Huhtanen et al., 2015). The between-animal CV of slightly below $10 \%$ for the MIR estimates was within the range of between-animal CV reported by Grainger et al. (2007). With the current GF data, clearly higher levels of variation (CV of 13-14\%) were observed as being within the range reported in other GF studies $(12 \%$, Renand and Maupetit, 2016; 9-17\%, Rischewski et al., 
2017). With RC, Oss et al. (2016) and Rischewski et al. (2017) found CV between 8 and 13\%, whereas others (Grainger et al., 2007; Garnsworthy et al., 2012) found markedly higher values. Overall, these findings show that repeatability and CV of MIR estimates were comparable to those of $\mathrm{CH}_{4}$ data measured using the GF system. The CCC between the MIR and GF were within the range of CCC (0.10-0.34) obtained in studies comparing $\mathrm{GF}$ with the $\mathrm{SF}_{6}$ tracer technique (Hammond et al., 2015; Hristov et al., 2016), which highlights the difficulty of measuring $\mathrm{CH}_{4}$ accurately under practical conditions, as indicated by the low concordance between different methods. However, the comparison of GF and MIR yielded results that were close to the findings of Hammond et al. (2015) and Hristov et al. (2016), who compared the RC with the $\mathrm{SF}_{6}$ tracer technique, meaning MIR prediction mainly using the $\mathrm{SF}_{6}$ tracer technique as the reference method leads to expected concordance.

\section{Minimal Frequency of $\mathrm{CH}_{4}$ Data Collection}

Persistence of Category Differences with Increasing Measurement Period. The present results did not reveal systematic changes in the significance of category differences when data were averaged across 7,14 , or $28 \mathrm{~d}$. This outcome applied to both period and feeding regimen in the model, and thus it indicates that a 7-d period of measurement could be sufficient for reliable data on category differences.

Changes of Frequency in Repeatability. The repeatability of the MIR results increased from 0.34 to 0.55 when the estimation period was extended from 7 to $28 \mathrm{~d}$. This result indicates that, based on weekly milk sampling, averaging 4 sets over a 28 -d period would increase the precision of MIR estimates. It remains to be shown if the same result can be achieved by averaging monthly data across 4 mo, but confounding factors might undermine success. Concerning GF, Renand and Maupetit (2016) recently recommended performing at least 7 to $14 \mathrm{~d}$ of measurements yielding at least 20 to 30 spot measurement events per measurement period per cow. In the current study, repeatability increased slightly, to 0.68 , when the measurement period was extended from 7 to $14 \mathrm{~d}$. However, a further extension to $28 \mathrm{~d}$ decreased repeatability possibly because of the increasing impact of trends caused by DIM or variations in diet composition. Using GF, Renand and Maupetit (2016) also found repeatability of 0.68 in beef heifers when data were averaged over $14 \mathrm{~d}$, with a lower repeatability when data were averaged only over $7 \mathrm{~d}$. Other authors reported higher repeatabilities with GF for MeP averaged over 5 to 45 d (Arbre et al., 2016; Manafiazar et al., 2016).
Changes of Frequency in Between-Cow Variability. Extending the frequency of assessment slightly reduced the $\mathrm{CV}$ between animals with MIR and GF in the 28-d period. This finding indicates that an extension of the periods affects the quality of the data for milk MIR estimates. Moreover, it indicates that the precision of data obtained is increased by extending the measurement period, which is also shown by increasing repeatability.

Changes of Frequency in CCC. The CCC increased with an extended frequency, indicating that the concordance became better and was in the same range found in comparing the $\mathrm{GF}$ and $\mathrm{SF}_{6}$ tracer techniques (Hammond et al., 2015; Hristov et al., 2016)

\section{Suitability of the 2 Methods to Categorize Animals into Low and High Emitters}

Groups selected for divergent $\mathrm{MeP}$ must retain their differences over time and across diets. Some previous studies with dairy cows did not show a consistent ranking in individual animals over time (Münger and Kreuzer, 2008; Rischewski et al., 2017). Others were able to display consistent between-animal differences in $\mathrm{CH}_{4}$ yield (MeY, g/ $\mathrm{kg}$ of DMI) over an experimental period of $3 \mathrm{mo}$ and between 2 different diets with growing sheep (Pinares-Patiño et al., 2011). Jonker et al. (2017) showed that the progeny of sheep selected for low and high $\mathrm{MeY}$, as determined by $\mathrm{RC}$, also had different MeP. Other studies give clear indications that MeP, MeI, and MeY are heritable traits $\left(\mathrm{h}^{2}=0.21\right.$ for $\mathrm{MeP}$ and 0.25 to 0.22 for MeI; Lassen and Løvendahl, 2016; Kandel et al., 2017). In the present study, we showed a lack of interaction between category and time, which means that groups of animals categorized by means of the milk MIR spectra estimation for their respective MeP maintained their initial differentiation over 5 mo, independent of the method of $\mathrm{MeP}$ assessment used. The differences among the high- and low-emitting cows persisted, regardless of whether data were averaged over 7,14 , or $28 \mathrm{~d}$. To our knowledge, no other study has reported that categorization of cows into low and high emitters is possible based on proxies, as confirmed by simultaneous measurements of MeP. Garnsworthy et al. (2012) measured MeP of dairy cows in the milking parlor with an infrared $\mathrm{CH}_{4}$ analyzer over a 5-mo period under commercial conditions. They showed high repeatability of ranking according to $\mathrm{MeP}$ and consistent differences between individual animals across time. In addition, they described a significant sire effect on $\mathrm{MeP}$, confirming a genetic component of MeP. Kandel et al. (2017) found a close correlation in the estimated breeding values of dairy cows between first and second lactation for MIR MeP and MeI, suggesting that the 
ranking of animals is also persistent across 2 consecutive lactations.

The present results are applicable on the condition that cows originate from 1 farm and that groups always undergo the same feeding protocols. Results from cows on different farms might differ, but at least the persistence of the differentiation across the 2 contrasting feeding regimens in the present study indicates an underlying category effect. Consistent with this, Jonker et al. (2017) reported that differences in MeY in selection lines of sheep, selected beforehand on an alfalfa pellet-based diet, were also present to a similar magnitude when grazing pasture. In another study, repeated measurements of $\mathrm{MeP}$ on contrasting diets (pellets vs. grass) revealed that sheep maintained their initial categorization, although the magnitude of difference between the 2 category groups varied by diet (PinaresPatiño et al., 2011).

An important side aspect of the present study was that, based on the GF measurements, the selection for $\mathrm{MeP}$ was not able to achieve a similarly great differentiation in MeI. In the beginning, a certain differentiation in MeI was found between categories, but this difference vanished with progressing stages of lactation and changes in the diet composition. Indirect genetic selection for a lower MeI was previously found to be successful by selecting for ECM, which reduced MeP by $15 \%$ in the first 3 lactations (Knapp et al., 2014). However, selecting directly for MeI is possible by combining MIR MeP and ECM results obtained on the same recording date on the farm. The repeated measures correlation was fairly low between the 2 applied methods and clearly lower than the repeated measures correlation between the laser $\mathrm{CH}_{4}$ detector and the GF device (0.66; Sorg et al., 2018), indicating that ranking individual cows according to $\mathrm{MeP}$ was different with MIR and GF and categorizing a group of animals is possible with MIR alone. The lack of agreement between cows on an individual level might be caused by the different feed or nutrient intake between cows and within cows over time.

\section{Eating and Ruminal Characteristics of Cows Categorized as Low $\mathrm{CH}_{4}$ Emitters}

The search for characteristics of low-emitting dairy cows is intensive and ongoing. Dry matter intake and fractional outflow rate of feed particles from the rumen are well known to be among the main factors responsible for variations in $\mathrm{MeP}$ among ruminants (Lyons et al., 2018). They determine provision of substrate and time for fermenting the substrate, and they thus eventually also determine the synthesis of $\mathrm{CH}_{4}$. However, Robinson et al. (2015) did not observe differences in DMI between high and low MeY sheep. The high- and low-emitting cows in the present study also did not differ significantly in DMI, which is why no positive relationship between $\mathrm{MeP}$ and DMI was found. Although the level of DMI was within a plausible range, we cannot completely exclude the possibility that inaccuracies in DMI estimation occurred with the double alkane method, but this issue would have applied to both groups equally. However, the indications of (nonsignificant) variation found in the ruminal VFA profile gives some evidence to explain the group differences in MeP. Fiber-fermenting bacteria, which produce predominantly acetate, provide the majority of $\mathrm{H}_{2}$ as a substrate for methanogenesis, whereas propionate is an alternative $\mathrm{H}_{2}$ sink without concomitant $\mathrm{CH}_{4}$ production (Moss et al., 2000). Indeed, the ruminal fluid of the low-emitting cows tended to have a lower acetate-to-propionate ration compared with that of the high-emitting cows. Previous studies performed with sheep indicated that low emitters are also characterized by high feed conversion efficiency (Pinares-Patiño et al., 2013), low residual feed intake (Hegarty et al., 2007), short digesta retention time, and small rumen size (Goopy et al., 2014). Moreover, the shorter daily eating time observed in low-emitting cows might be a further characteristic of low-emitting animals, which itself might be associated with a shorter digesta retention time. Pinares-Patiño et al. (2007) also found a positive correlation between daily MeP and eating time, but the low repeatability of the data precluded any meaningful interpretation.

\section{CONCLUSIONS}

Based on the results, we conclude that the $\mathrm{CH}_{4}$ estimation by means of analyzing milk MIR spectra is an appropriate method for establishing categories of cows according to low and high MeP. These findings widely agree with measurement results using the GF device. Average $\mathrm{MeP}$ values for categories were also quite similar when determined with MIR and GF, and concomitant category tendencies in ruminal VFA profiles supported the plausibility of the results. One of the most important findings of our study was that differences between the 2 categories were persistent over the course of $5 \mathrm{mo}$ and across 2 contrasting feeding regimens. Accordingly, it was possible to identify 2 different cow categories with the MIR estimates, which might be useful in categorizing daughters of bulls in progeny testing. For individual cows, however, a lack of agreement was found between the 2 methods. Further studies with more accurate measurements (e.g., using $\mathrm{RC}$ ) need to show whether the accuracy of predicting $\mathrm{CH}_{4}$ emissions of individuals is sufficient to be useful 
in breeding. The results also showed that the groups of cows categorized by their MeP did not differ consistently and clearly in MeI, when the GF system and MIR spectra were used. From an environmental point of view, producing milk with as few $\mathrm{CH}_{4}$ emissions as possible is much more important than having cows that differ concomitantly in $\mathrm{MeP}$ and milk yield. The findings therefore indicate that prospecting for low emitters has to be done based on MeI or on MeP adjusted for factors describing milk yield. Concerning the minimal test period for assessing $\mathrm{MeP}$, the present data suggest $14 \mathrm{~d}$ for GF measurements, comprising 35 spot measurements. With MIR, collecting milk samples once per week for a 4-wk period is optimal, but taking 1 to 2 samples per month, along with regular control, may lead to acceptable results. Future investigations should include cows from different farm origins to test the robustness of estimates with MIR across farms, ideally spanning the complete lactation of cows.

\section{ACKNOWLEDGMENTS}

The authors thank the experimental farm and laboratories of Agroscope in Posieux for the technical assistance from their staff. We thank the Centre Wallon de Recherches Agronomiques (CRA-W), Gembloux, Belgium, and the Université de Liège-Gembloux AgroBio Tech (GxABT), Liège, Belgium, for providing the equations permitting predictions of methane emission by dairy cows from MIR spectra. The study was supported by the European Cooperation in Science and Technology (COST Action FA 1302, 'MethaGene'); the Swiss State Secretariat for Education, Research and Innovation, Bern, Switzerland; and Qualitas AG, Zug, Switzerland.

\section{REFERENCES}

Agroscope. 2019a. Feeding recommendations for ruminants (in German). Accessed Feb. 23, 2019. https://www.agroscope .admin.ch/agroscope/de/home/services/dienste/futtermittel/ fuetterungsempfehlungen-wiederkaeuer.html.

Agroscope. 2019b. Swiss feedbase (in German). Accessed Feb. 23, 2019. https://www.agroscope.admin.ch/agroscope/de/home/ services/dienste/futtermittel/futtermitteldatenbank.html/.

AOAC International. 1995. Official Methods of Analysis. 16th ed. AOAC International, Arlington, VA.

Arbre, M., Y. Rochette, J. Guyader, C. Lascoux, L. M. Gómez, M. Eugène, D. Morgavi, G. Renand, M. Doreau, and C. Martin. 2016. Repeatability of enteric methane determinations from cattle using either the $\mathrm{SF}_{6}$ tracer technique or the GreenFeed system. Anim. Prod. Sci. 56:238-243.

Bakdash, J. Z., and L. R. Marusich. 2018. rmcorr: Repeated Measures Correlation. R Package Version 3.2.1. https://cran.r-project.org/ package $=$ rmcorr.

Bernard, L., C. Leroux, and Y. Chilliard. 2008. Expression and nutritional regulation of lipogenic genes in the ruminant lactating mammary gland. Pages 67-108 in Bioactive Components of Milk. Vol. 606. Z. Bösze, ed. Springer, New York, NY. de Haas, Y., M. Pszczola, H. Soyeurt, E. Wall, and J. Lassen. 2017. Phenotypes to genetically reduce greenhouse gas emissions in dairying. J. Dairy Sci. 100:855-870.

Dorich, C. D., R. K. Varner, A. B. D. Pereira, R. Martineau, K. J Soder, and A. F. Brito. 2015. Use of a portable, automated, opencircuit gas quantification system and the sulfur hexafluoride tracer technique for measuring enteric methane emissions in Holstein cows fed ad libitum or restricted. J. Dairy Sci. 98:2676-2681.

Garnsworthy, P. C., J. Craigon, J. H. Hernandez-Medrano, and N Saunders. 2012. Variation among individual dairy cows in methane measurements made on farm during milking. J. Dairy Sci. 95:3181-3189.

Gill, J. L. 1986. Repeated measurement: Sensitive tests for experiments with few animals. J. Anim. Sci. 63:943-954.

Goopy, J. P., A. Donaldson, R. Hegarty, P. E. Vercoe, F. Haynes, M. Barnett, and V. H. Oddy. 2014. Low-methane yield sheep have smaller rumens and shorter ruminal retention time. Br. J. Nutr. 111:578-585.

Graf, C. M., M. Kreuzer, and F. Dohme. 2005. Effects of supplemental hay and corn silage versus full-time grazing on ruminal $\mathrm{pH}$ and chewing activity of dairy cows. J. Dairy Sci. 88:711-725.

Grainger, C., T. Clarke, S. M. McGinn, M. J. Auldist, K. A. Beauchemin, M. C. Hannah, G. C. Waghorn, H. Clark, and R. J. Eckard 2007. Methane emissions from dairy cows measured using the sulfur hexafluoride $\left(\mathrm{SF}_{6}\right)$ tracer and chamber techniques. J. Dairy Sci. 90:2755-2766

Grandl, F., S. L. Amelchanka, M. Furger, M. Clauss, J. O. Zeitz, M. Kreuzer, and A. Schwarm. 2016. Biological implications of longevity in dairy cows: 2 . Changes in methane emissions and efficiency with age. J. Dairy Sci. 99:3472-3485.

Grelet, C., J. A. F. Pierna, P. Dardenne, V. Baeten, and F. Dehareng. 2015. Standardization of milk mid-infrared spectra from a European dairy network. J. Dairy Sci. 98:2150-2160.

Hall, M. B., W. H. Hoover, J. P. Jennings, and T. K. M. Webster. 1999. A method for partitioning neutral detergent-soluble carbohydrates. J. Sci. Food Agric. 79:2079-2086.

Hammond, K. J., D. J. Humphries, L. A. Crompton, C. Green, and C. K. Reynolds. 2015. Methane emissions from cattle: Estimates from short-term measurements using a GreenFeed system compared with measurements obtained using respiration chambers or sulphur hexafluoride tracer. Anim. Feed Sci. Technol. 203:41-52.

Hammond, K. J., G. C. Waghorn, and R. S. Hegarty. 2016. The GreenFeed system for measurement of enteric methane emission from cattle. Anim. Prod. Sci. 56:181-189.

Hegarty, R. S., J. P. Goopy, R. M. Herd, and B. McCorkell. 2007. Cattle selected for lower residual feed intake have reduced daily methane production. J. Anim. Sci. 85:1479-1486.

Holmes, C. D., M. J. Prather, O. A. Søvde, and G. Myhre. 2013. Future methane, hydroxyl, and their uncertainties: Key climate and emission parameters for future predictions. Atmos. Chem. Phys. $13: 285-302$.

Hristov, A. N., J. Oh, F. Giallongo, T. Frederick, M. T. Harper, H. Weeks, A. F. Branco, W. J. Price, P. J. Moate, and M. H. Deighton. 2016. Comparison of the GreenFeed system with the sulfur hexafluoride tracer technique for measuring enteric methane emissions from dairy cows. J. Dairy Sci. 99:5461-5465.

Hristov, A. N., J. Oh, F. Giallongo, T. Frederick, H. Weeks, P. R. Zimmerman, M. T. Harper, R. A. Hristova, R. S. Zimmerman, and A. F. Branco. 2015. The use of an automated system (GreenFeed) to monitor enteric methane and carbon dioxide emissions from ruminant animals. J. Vis. Exp. 103:52904.

Huhtanen, P., E. H. Cabezas-Garcia, S. Utsumi, and S. Zimmerman. 2015. Comparison of methods to determine methane emissions from dairy cows in farm conditions. J. Dairy Sci. 98:3394-3409.

Jonker, A., S. Hickey, C. Pinares-Patiño, J. McEwan, S. Olinga, A. Díaz, G. Molano, S. MacLean, E. Sandoval, R. Harland, D. Birch, B. Bryson, K. Knowler, and S. Rowe. 2017. Sheep from low-methane-yield selection lines created on alfalfa pellets also have lower methane yield under pastoral farming conditions. J. Anim. Sci. 95:3905-3913. 
Kandel, P. B., M.-L. Vanrobays, A. Vanlierde, F. Dehareng, E. Froidmont, N. Gengler, and H. Soyeurt. 2017. Genetic parameters of mid-infrared methane predictions and their relationships with milk production traits in Holstein cattle. J. Dairy Sci. 100:5578-5591.

Knapp, J. R., G. L. Laur, P. A. Vadas, W. P. Weiss, and J. M. Tricarico. 2014. Enteric methane in dairy cattle production: Quantifying the opportunities and impact of reducing emissions. J. Dairy Sci. 97:3231-3261.

Lassen, J., and P. Løvendahl. 2016. Heritability estimates for enteric methane emissions from Holstein cattle measured using noninvasive methods. J. Dairy Sci. 99:1959-1967.

Lyons, T., A. Bielak, E. Doyle, and B. Kuhla. 2018. Variations in methane yield and microbial community profiles in the rumen of dairy cows as they pass through stages of first lactation. J. Dairy Sci. 101:5102-5114.

Manafiazar, G., S. Zimmerman, and J. A. Basarab. 2016. Repeatability and variability of short-term spot measurement of methane and carbon dioxide emissions from beef cattle using GreenFeed emissions monitoring system. Can. J. Anim. Sci. 97:118-126.

Marschner, I., and M. W. Donoghoe. 2018. glm2: Fitting Generalized Linear Models. R Package Version 1.2.1. https://CRAN.RProject .org $/$ package $=$ glm 2 .

Mayes, R. W., C. S. Lamb, and P. M. Colgrove. 1986. The use of dosed and herbage n-alkanes as markers for the determination of herbage intake. J. Agric. Sci. 107:161-170.

Moss, A. R., J.-P. Jouany, and J. Newbold. 2000. Methane production by ruminants: Its contribution to global warming. Ann. Zootech. 49:231-253.

Münger, A., and M. Kreuzer. 2008. Absence of persistent methane emission differences in three breeds of dairy cows. Aust. J. Exp. Agric. 48:77-82.

Oddy, V. H., A. J. Donaldson, M. Cameron, J. Bond, S. Dominik, and D. L. Robinson. 2018. Variation in methane production over time and physiological state in sheep. Anim. Prod. Sci. 59:441-448.

Oss, D. B., M. I. Marcondes, F. S. Machado, L. G. R. Pereira, T. R. Tomich, G. O. Ribeiro, M. L. Chizzotti, A. L. Ferreira, M. M. Campos, R. M. Maurício, A. V. Chaves, and T. A. McAllister. 2016. An evaluation of the face mask system based on short-term measurements compared with the sulfur hexafluoride $\left(\mathrm{SF}_{6}\right)$ tracer, and respiration chamber techniques for measuring $\mathrm{CH}_{4}$ emissions. Anim. Feed Sci. Technol. 216:49-57.

Pinares-Patiño, C. S., S. M. Hickey, E. A. Young, K. G. Dodds, S. MacLean, G. Molano, E. Sandoval, H. Kjestrup, R. Harland, C. Hunt, N. K. Pickering, and J. C. McEwan. 2013. Heritability estimates of methane emissions from sheep. Animal 7(Suppl. 2):316-321.

Pinares-Patiño, C. S., J. C. McEwan, K. G. Dodds, E. A. Cárdenas, R. S. Hegarty, J. P. Koolaard, and H. Clark. 2011. Repeatability of methane emissions from sheep. Anim. Feed Sci. Technol. 166:210-218.

Pinares-Patiño, C. S., G. C. Waghorn, A. Machmüller, B. Vlaeming, G. Molano, A. Cavanagh, and H. Clark. 2007. Methane emissions and digestive physiology of non-lactating dairy cows fed pasture forage. Can. J. Anim. Sci. 87:601-613.

Pinheiro, J., D. Bates, S. DebRoy, D. Sarkar, and R Core Team. 2017. nlme: Linear and Nonlinear Mixed Effects Models. R Package Version 3.1-131. https://CRAN.Rproject.org/package=nlme.

R Core Team. 2018. R: A Language and Environment for Statistical Computing. R Foundation for Statistical Computing, Vienna, Austria. https://www.R-project.org.

Renand, G., and D. Maupetit. 2016. Assessing individual differences in enteric methane emission among beef heifers using the GreenFeed Emission Monitoring system: Effect of the length of testing period on precision. Anim. Prod. Sci. 56:218-223.

Rischewski, J., A. Bielak, G. Nürnberg, M. Derno, and B. Kuhla. 2017. Ranking dairy cows for methane emissions measured using respiration chamber or GreenFeed techniques during early, peak, and late lactation. J. Anim. Sci. 95:3154-3159.
Robinson, D. L., J. P. Goopy, R. S. Hegarty, and V. H. Oddy. 2015. Comparison of repeated measurements of methane production in sheep over 5 years and a range of measurement protocols. J. Anim. Sci. 93:4637-4650.

Rombach, M., A. Münger, J. Niederhauser, K.-H. Südekum, and F. Schori. 2018. Evaluation and validation of an automatic jaw movement recorder (RumiWatch) for ingestive and rumination behaviors of dairy cows during grazing and supplementation. J. Dairy Sci. 101:2463-2475.

Shetty, N., G. Difford, J. Lassen, P. Løvendahl, and A. J. Buitenhuis. 2017. Predicting methane emissions of lactating Danish Holstein cows using Fourier transform mid-infrared spectroscopy of milk. J. Dairy Sci. 100:9052-9060.

Sorg, D., G. F. Difford, S. Mühlbach, B. Kuhla, H. H. Swalve, J. Lassen, T. Strabel, and M. Pszczola. 2018. Comparison of a laser methane detector with the GreenFeed and two breath analysers for on-farm measurements of methane emissions from dairy cows. Comput. Electron. Agric. 153:285-294.

Soyeurt, H., F. Dehareng, N. Gengler, S. McParland, E. Wall, D. P. Berry, M. Coffey, and P. Dardenne. 2011. Mid-infrared prediction of bovine milk fatty acids across multiple breeds, production systems, and countries. J. Dairy Sci. 94:1657-1667.

Steinfeld, H., P. Gerber, T. D. Wassenaar, V. Castel, M. Rosales, and C. De Haan. 2006. Livestock's long shadow. FAO, Rome, Italy.

Stevenson, M., T. Nunes, C. Heuer, J. Marshall, J. Sanchez, R. Thornton, J. Reiczigel, J. Robison-Cox, P. Sebastiani, P. Solymos, K. Yoshida, G. Jones, S. Pirikahu, S. Firestone, R. Kyle, J. Popp, and M. Jay. 2019. epiR: Tools for the Analysis of Epidemiological Data. R Package Version 3.2.1. https://cran.r-project.org/package $=$ epiR.

Stoffel, M. A., S. Nakagawa, and H. Schielzeth. 2018. rptR: Repeatability Estimation for Gaussian and Non-Gaussian Data. R Package Version 3.2.1. https://CRAN.Rproject.org/package $=$ rptR.

Thanner, S., F. Dohme-Meier, S. Görs, C. C. Metges, R. M. Bruckmaier, and F. Schori. 2014. The energy expenditure of 2 Holstein cow strains in an organic grazing system. J. Dairy Sci. 97:2789-2799.

van Gastelen, S., and J. Dijkstra. 2016. Prediction of methane emission from lactating dairy cows using milk fatty acids and midinfrared spectroscopy. J. Sci. Food Agric. 96:3963-3968.

Vanlierde, A., H. Soyeurt, N. Gengler, F. G. Colinet, E. Froidmont, M. Kreuzer, F. Grandl, M. Bell, P. Lund, D. W. Olijhoek, M. Eugène, C. Martin, B. Kuhla, and F. Dehareng. 2018. Development of an equation for estimating methane emissions of dairy cows from milk Fourier transform mid-infrared spectra by using reference data obtained exclusively from respiration chambers. J. Dairy Sci. 101:7618-7624.

Vanlierde, A., M.-L. Vanrobays, F. Dehareng, E. Froidmont, H. Soyeurt, S. McParland, E. Lewis, M. H. Deighton, F. Grandl, M. Kreuzer, B. Gredler, P. Dardenne, and N. Gengler. 2015. Innovative lactation-stage-dependent prediction of methane emissions from milk mid-infrared spectra. J. Dairy Sci. 98:5740-5747.

Vanlierde, A., M.-L. Vanrobays, N. Gengler, P. Dardenne, E. Froidmont, H. Soyeurt, S. McParland, E. Lewis, M. H. Deighton, M. Mathot, and F. Dehareng. 2016. Milk mid-infrared spectra enable prediction of lactation-stage-dependent methane emissions of dairy cattle within routine population-scale milk recording schemes. Anim. Prod. Sci. 56:258-264

Waghorn, G. C., A. Jonker, and K. A. Macdonald. 2016. Measuring methane from grazing dairy cows using GreenFeed. Anim. Prod. Sci. 56:252-257.

Waghorn, G. C., A. Jonker, and R. McAuliffe. 2018. GreenFeed standard operating procedure. Accessed July 8, 2019. https: / / globalresearchalliance.org/wp-content/uploads / 2018/08/ GreenFeeds-SOP__final.pdf. 